\title{
A Qualitative Analysis of Slot Clubs as Drivers of Casino Loyalty
}

by FLAVIA HENDLER and KATHRYN A. LATOUR

The slot club is a very common type of loyalty program in the casino industry. In this research, the authors look at the deep meanings and emotions of a slot club for tourists and frequent local customers at a Las Vegas mega casino resort using an in-depth interview technique, the Zaltman Metaphor Elicitation Technique (ZMET). Results indicate that the opportunities for casino loyalty programs to establish emotional bonds with the customer lie in the capacity of reflecting human qualities in the slot club service delivery process, such as memory, creativity, and flexibility. The results also indicate that the slot club brings different meanings to different customer groups and that these emotional connections (or lack thereof) are best elucidated via this qualitative research technique that uses images, rather than words, to guide the in-depth interview. The authors discuss the implications of the results for loyalty programs as well as how this research technique might be used in other sectors of the hospitality industry.

Keywords: casino management; slot clubs; Las Vegas resorts

he question of whether loyalty programs really induce customer loyalty is not a new one; in fact, that issue has been raised by a number of researchers in both hospitality and marketing (Dowling and Uncles 1997; Uncles, Dowling, and Hammond 2003; Yi and Jeon 2003; Sharp and Sharp 1997; Whyte 2004). The study described here was initiated because the management of a mega casino resort in Las Vegas questioned the value of its existing loyalty program. The managers suspected that customers saw the program as 
an opportunity to acquire product discounts without developing any deep-seated loyalty to the property. However, when the property conducted a series of phone interviews, focus groups, and online surveys to assemble a list of the twenty features customers said they desired in a loyalty program, discounts and room upgrades topped the list. What we noticed about those resultsmostly obtained from open-ended questions geared toward identifying the desirable features in a loyalty program-is that they omitted any emotional aspect of the service experience and how customers felt about their relationship with the property. The results of this initial phase of studies contrasted with increasing evidence that loyalty encompasses attitudinal and emotional dimensions (Dick and Basu 1994; Day 1969; Jacoby and Kyner 1973; Jacoby and Chestnut 1978; Backman and Crompton 1991). In addition, management felt it still lacked an understanding of how to use the loyalty program to create a stronger relationship with customers.

As part of the effort to address this question, we investigated the deeper meanings of the resort experience and of the loyalty program for two segments of customers: tourists and the local frequent slot players. We focused on the mega resort's existing loyalty program (known as the slot club). ${ }^{1}$ The study of the deep emotional meanings of loyalty in casinos is particularly interesting because the purchase motives in gaming are hedonic, highly emotional, and perhaps even irrational. $^{2}$ We therefore selected a research methodology-the Zaltman Metaphor Elicitation Technique (ZMET) - that has been used by researchers to uncover consumers' unconscious motives. The ZMET can be particularly useful for uncovering meanings associated with the gaming experience, since they may escape the customers' own awareness. In addition, the research conducted by the mega casino resort did not differentiate between types of players and their view of the slot program. We were convinced that making such a distinction could reveal important insights into the role of the slot club at the property. Though our context is gaming, we believe that the insights for this loyalty program apply to nearly any hospitality loyalty program. In fact, because casinos have long maintained loyalty programs and now apply customer relationship management (CRM) software, casinos are often used as models in other industries. ${ }^{3}$

Our investigation is organized as follows: First, we discuss some of the problems faced by loyalty programs overall, and then we focus more specifically on casino loyalty programs. Some of the challenges of making this analysis stem from the difficulty in defining and measuring customer loyalty, and we present an overview of that research. We then explain the ZMET and provide our rationale for choosing the ZMET for our methodology. We next discuss our study, beginning with

1. Casino slot clubs are the entities in the casinos that operationalize the collection of customer data and the delivery of loyalty program benefits for slot customers. Some of the common benefits offered by such clubs are room discounts or complimentary stays, complimentary food and beverage, participation in parties usually called special events, free flight tickets, gifts, cash back, and promotional offers aimed to stimulate repeat purchase and increase play.

2. As argued by Browne, Kaldenberg, and Brown (1992, 93), "In its pure sense game-playing is hedonic consumption, characterized by being spontaneous and pleasurable, providing feelings of competence and control, and by being distinct from work." For a description of the nature of hedonic experience and its association to mental constructs such as multisensory image and emotional arousal, see Hirschman and Holbrook (1982).

3. For a detailed discussion of business analytics at a casino, see Loveman (2003). For an example of the use of casino practices as reference, see Jeffery and Leliveld (2004). 
our sample choice and selection process, and then moving to the interview procedure and research results. We end with a discussion of the implications for casino loyalty programs in particular and more generally for hospitality loyalty programs. We also discuss the potential use of the ZMET in other sectors of the hospitality industry.

\section{Problems with Loyalty Programs}

Despite the wide use of loyalty programs in hospitality, research suggests that the demand-enhancing potential of loyalty programs is limited (Dowling and Uncles 1997). One of the major problems facing those who offer loyalty programs is the fact that the direct economic benefits offered to customers translate into alternative forms of discounting and product bundling that can be easily copied by competitors. This creates a potential discounting death spiral as firms feel obliged to constantly match benefits. This is a form of price war, which turns loyalty programs into costly liabilities. Another problem is that offers intended to provide differentiated and customized service for loyal customers can be costly and operationally challenging.

\section{Casino Loyalty Programs}

Casinos have long applied CRM concepts of giving the best treatment to their best customers. For example, casinos have always had hosts who take charge of detailed personal arrangements for their premium customers. The measures to create personal relationships include providing complimentary meals, presidential suites, private jets, and exclusive cruises. As the casinos have expanded with the development of megaresort hotels, there has been a need to make the CRM programs more technologically sophisticated. Slot clubs or players clubs are examples of these new-style CRM programs. Casinos use individual slot club cards to track detailed gaming-related information on their patrons, particularly on slot machines. The information thus recorded is highly accurate since it covers even penny transactions. The purchase information allows the casino to customize offers and benefits to players according to amount wagered, which in some cases is combined with additional demographic and behavioral data (e.g., preferences, frequency of visits).

The competitive advantage to the casino from such a program is limited, however, because slot club benefits such as cash back, complimentary rooms, access to events, and exclusive parties are easy for competitors to match. Although casinos face elevated costs due to loyalty efforts, it is not clear whether such efforts in fact create loyalty. To make matters worse, Lucas, Kilby, and Santos (2002) demonstrated how the spiraling acquisition costs for premium players (high-rollers) have eroded profit margins to the point of making some customers unprofitable and even creating a players' advantage. In response to that challenge, Harrah's, for one, developed a marketing strategy that does not focus on this high-end market. A thorough assessment may show that current practices aimed to increase loyalty in other markets may also prove ineffective. As part of such an assessment, we must understand the role of casino loyalty programs on customer loyalty.

\section{Does Belonging to a Loyalty Program Equate to Consumer Loyalty? Getting to a Definition of Loyalty}

The difficulties of measuring the impact of a casino loyalty program start with measuring loyalty itself. First of all, there is no unanimously accepted definition of loyalty. In both the marketing and hospitality fields, researchers and practitioners have applied behavioral measures such as repeat purchases, incremental visits, or incremental revenues (share of wallet) as indicators of customer loyalty. However, the use of behavioral measures has limitations because 
behavior does not necessarily indicate affect. To illustrate, even though two customers might have the same purchase patterns, one might hold preference toward a brand, while the other may buy simply as a result of convenience or passive acceptance of the brand. It is reasonable to expect that a lack of preference could easily be overcome by an aggressive competitor. Therefore, measuring purchase patterns alone will not provide a thorough assessment of customer loyalty. In addition to the intrinsic challenges in using behavioral measures, it is hard to identify how loyalty programs affect those measures. As pointed out by Dowlings and Uncles (1997), the quasi-experimental nature of most studies entail methodological difficulties, such as lack of a control group. It is, in fact, difficult to imagine a service provider denying access to a loyalty membership program to some customers to compare their behavior to that of program members. However, if we chose to simply compare members and nonmembers, we would overestimate the effects of the program because nonmembers would probably be mostly nonfrequent users of the brand (thus introducing a self-selection bias).

There is conceptual support in marketing and hospitality for a definition of loyalty that goes beyond behavioral measures and encompasses attitudinal measures that include trust and commitment (Pritchard, Havitz, and Howard 1999; Fournier and Yao 1997; Hallberg 2004). Along these lines, in a study of a casino slot club, Baloglu (2002) proposed a two-dimensional approach to consumer loyalty, which assesses attitudinal loyalty by measuring commitment, emotional attachment, and trust. Other authors have provided evidence of the emotional components of loyalty for hospitality firms (Mattila 2006, 2001a; Barsky and Nash 2002). These findings, along with increasing evidence that emotions and logical reasoning jointly affect our behavior, ${ }^{4}$ suggest that understanding the emotional components of the relationship is a requirement for a comprehensive picture of the consumer attitudes towards a brand - and, consequently, of consumer loyalty. Barsky and Nash (2002) proposed specific loyalty-inducing emotions for different segments in the hotel industry, but their study did not refer specifically to casino resorts nor to slot programs. It is noteworthy that loyalty programs are subject to operational and strategic failures, and there is research evidence of negative emotional outcomes of such programs (Stauss, Schmidt, and Schoeler 2005). A comprehensive view of the emotions associated with loyalty efforts may include negative feelings which have not been addressed in hospitality loyalty studies. In fact, Mattila (2006) mentioned the omission of consideration of emotions as a limitation of her loyalty study in a context of service failure (she attributed this limitation to the methodology utilized) (Mattila 2001b).

Wirtz, Mattila, and Lwin (forthcoming) addressed that omission by examining the relationship of loyalty programs to attitudinal loyalty and share of wallet. In a previous Cornell Quarterly issue, Mattila (2006) demonstrated how emotions color customers' perceptions of the loyalty program. Our study complements these findings by introducing a research tool that allows the consumer to express unconscious meanings as well as emotions associated with the program itself.

4. Zaltman (2003) explained that emotions are essential for sound decision making. To illustrate his point, he mentioned the example of Phineas Gage, whose head injury left his reasoning skills intact, but damages in his emotional capacities left him unable to make wise choices. For more information, see Damasio (1994). For a discussion of emotions and the unconcious in decision making, see Zaltman (2003). 


\section{Getting a Deeper Understanding of Casino Loyalty through the ZMET}

Though commonly used, traditional marketing research methods (e.g., questionnaires, focus groups) are not able to reach customers at a deep level. For the most part, such studies are based on customer self-reports and focus on the cognitive realm of the decision-making process (Zaltman 1997). In the case of understanding the value of a loyalty program, focusing only on the cognitive realm can be quite limiting. For example, at the casino analyzed in this study, management considers certain segments of customers to be highly value-driven and "savvy," because they take full advantage of the club benefits. It seems reasonable to consider that in answering a questionnaire such customers may indicate that cash or even the program itself are important purchase criteria simply because they will be afraid to jeopardize those benefits. In fact, as mentioned above, initial studies conducted at the mega resort casino using oral questionnaires indicated that these rational cash benefits were most desired. From a managerial standpoint, studies that conclude offering more and more cash benefits can lead the casino into a spiral of discounting product offerings and lowering its profit margin more and more over time-even to the point of losses. Additionally, if there were any emotional benefits from the club, these might be overlooked or (worse) hampered if such discounting resulted in decreased service quality (e.g., less personal attention, longer lines, change in casino ambience).

The local Vegas gambler has become quite sophisticated in searching out special deals offered by loyalty programs, abetted by numerous local newspaper columns and website blogs. ${ }^{5}$ When facing a survey or phone interview, some of those gamblers might not feel comfortable disclosing information to the interviewer that they feel would reduce their potential advantage at the casino. Additionally, some customers might be unaware of - or reluctant to admit - their true motives for loyalty program involvement. Therefore, we needed a methodology that explores consumers' emotions and unconscious motives as a means toward building a comprehensive understanding of the underlying dimensions of loyalty toward the casino brand and the loyalty program.

For this investigation, we selected the Zaltman Metaphor Elicitation Technique (ZMET). This method, where the interviewer uses participants' chosen images to probe for their metaphorical thinking about a particular issue, reflects the neuroscience premise that all thoughts are image-based (e.g., Damasio 1994; Pinker 1994, 1997). Focused on unearthing this subconscious content, ZMET assumes that much of this content is based in images, not words (Zaltman 2003). Thus far, this technique has been used in a variety of marketing settings and has been recently used to reveal some important insights for a museum located at a Las Vegas casino mega resort (Braun-LaTour, Hendler, and Hendler 2006). It has not yet, however, been used to explore the different dimensions of customer loyalty nor the meanings of loyalty programs.

A typical ZMET interview proceeds as follows: First, participants are contacted and asked to find images such as photos, clips from magazines, or other sources that represent their thoughts and feelings about a particular issue or brand. The participant is given several days to find these images and bring them to the interview

5. For an example, see the Neon section of Las Vegas' daily newspaper The Las Vegas Review Journal on Fridays. 
session. The one-on-one interview is guided by these images. The first question is typically, "How does this image reflect your thoughts and feelings about X . . . ?" and participants are guided by the interviewer to explore their deeper connections to the target brand or issue. The interviewer uses various approaches to encourage participants to clarify or provide examples of the ideas they present. In this way, meanings are obtained from the customer's standpoint. For example, one technique might be to ask participants to "widen the frame" of their image and describe what else might enter to better explain how they feel about their loyalty (in this instance, to the mega resort casino). They are also asked about important images that represent ideas for which they could not find relevant pictures.

Lasting approximately ninety minutes per participant, the ZMET interview process is flexible, and other projective techniques can be employed in addition to the picture and storytelling process that occurs in all ZMET studies. In our case, we used a triadic sorting process, sensory metaphors, and vignette creation. In the triadic sorting process, participants describe how two pictures differ from a third one, stimulating them to identify higher-level concepts and possibly helping form connecting ideas. Metaphor elicitation is used during different phases of the interview. One step involves asking the participant to metaphorically think about the topic (or brand) as represented in various senses. For instance, in this case we had them identify a color, a taste, a touch, a sound, and an emotion that would represent the mega resort hotel and the slot club. The ZMET interviewer constantly questions those metaphors to elaborate deeper meanings of the ideas presented by the subjects. In the vignette phase, participants are asked to create a story, or a movie, about the topic. The underlying idea is to convey a sense of motion and time, engaging different parts of the brain (Zaltman 2003).

\section{Sample Rationale and Selection Process}

Based on prior research Seyhmus Baloglu (2002) conducted on casino loyalty, we felt we needed to get a sample that represented different types of loyalty to the slot club. In his research, Baloglu identified three categories of local slot club loyal behavior, applying the following classification by Dick and Basu (1994): true loyal, low loyal, and spurious loyal (see Dick and Basu 1994; Day 1969; Jacoby and Kyner 1973; Jacoby and Chestnut 1978; Backman and Crompton 1991). In that article (published in this journal), Baloglu argued that having spurious loyal customers (i.e., those with low attitudinal and high behavioral loyalty) might be desirable and suggested a study of the relationship between profitability and percentage of loyalty segments. He also suggested analyzing the loyal behaviors of the nonlocals in Las Vegas.

In this study, we build on Baloglu's (2002) findings by comparing locals to nonlocals (tourists) in Las Vegas. In addition, our context is different: Baloglu focused on a casino that attracts local residents, whereas we focus on a mega casino resort that caters to both tourists and locals. Even though locals are frequent customers, their behavior and attitudes are expected to be different from those of tourists for various reasons. For instance, they are believed to be "savvy" players who optimize their chances with skill games and choose casino floors with high payouts, and they are also thought to be knowledgeable about different reward structures. Even though there has been no formal study comparing the profit margins earned from locals against those from nonlocals, we found only few 
references in trade publications about their behavior. ${ }^{6}$ As further evidence, at the casino we studied, 62 percent of the local customers are predominantly video poker players, and consequently, more than 50 percent of the local-generated revenues is from video poker machines. By contrast, 26 percent of the nonlocals are predominantly video poker players. Like the card game, video poker is a game involving skill in gauging odds, and the odds of winning are greater than those of wheel slot machines. A casino executive illustrates this when justifying a reduction in video poker pay tables: "Our [video] poker players are very savvy and recognize the games that give them the best advantage and promotional offers.... We value our poker customers, but as a business we need to be realistic" (Brokopp 2006).

Nevertheless, the locals market is pursued by Las Vegas casinos because locals are believed to contribute to marketing efforts with positive word of mouth and to fill gaps in demand by responding quickly to offers designed drive traffic during lowdemand times. In the particular property studied, locals are also sought for nonstay visits during periods when the hotel is full with high-paying but nongaming customers.

The sample, comprising local (Las Vegas residents) customers and tourist customers, was drawn from slot players at the casino in question. The majority of the respondents preferred not to disclose their gambling budget, but based on information provided by the casino the sample's average daily theoretical (ADT) drop was $\$ 757,{ }^{7}$ with the lowest at $\$ 216$ and the highest at $\$ 2,300$. These gamblers therefore represent the more moderate gambler at this resort. (Those who gamble less generally do not earn enough to quality for slot benefits, while those who gamble more are the "high rollers" and may not be typical.)

We conducted ZMET interviews with eight locals and eight tourist customers (one tourist interview was conducted simultaneously with a married couple). Given the intensity of the methodology, small samples are characteristic of ZMET studies. Zaltman's research shows that 90 to 95 percent of existing themes within a group emerge during the first seven to eight interviews, and a sample of twelve to twenty respondents is generally recommended in ZMET studies. ${ }^{8}$ The total sample in our study is sixteen, well within the recommended range that would allow us to learn the common constructs from both locals and tourists. The meanings that represent the differences between these two groups might show slight differences in a larger sample, but based on previous research with ZMET, the core findings would most likely remain the same.

6. According to Bill Thompson, professor of public administration at the College of Business and Economics at the University of Nevada, Las Vegas, "The local casinos give better odds because the players are savvy" (cited in Domenici n.d.). According to casino executive Ron Lurie, "Local customers are pretty savvy, and to be successful, you have to know what's important to them" (cited in Stutz 2007). A systematic examination of the term "savvy" in the casino industry and its appropriateness to different casino segments can be a fertile ground for future research.

7. Average daily theoretical (ADT) is used by many casinos as a prediction of the daily casino revenues generated by a player. It is calculated as the product of the casino hold and the total daily amount wagered. Casino hold corresponds to the house advantage, and it is the theoretical percentage of each bet that stays with the casino. For example, if a gambler bets $\$ 1,000$ a day in a game with a 5 percent hold, his ADT is $\$ 50$. In such a game, the customers in our sample gamble at least $\$ 6,000$.

8. See Zaltman $(1997,432)$ as well as Zaltman and Coulter (1995). Furthermore, Griffin and Hauser (1993) found that as many ideas surface in ten one-to-one interviews as do in ten focus groups of eight participants each. 
Exhibit 1:

Slot Participant Information

\begin{tabular}{lcccl}
\hline Name & Gender & Age & Gambling Budget (\$) & City of Origin \\
\hline Jim & M & 67 & $15,000 /$ trip & California \\
Miriam & F & 64 & NA & Florida \\
Elvira & F & 60 & $2,000 /$ trip & California \\
Kristine & F & 52 & $4,000 /$ trip & Arizona \\
Robert & M & 75 & NA & Illinois \\
Mia & F & 67 & $5,000 /$ trip & Illinois \\
Penn & M & 48 & $5,000 /$ trip & California \\
Paul & M & 57 & NA & Arizona \\
Julia & F & 54 & NA & Las Vegas \\
Beatrice & F & 64 & NA & Las Vegas \\
Ester & F & 48 & $8,000 /$ month & Las Vegas \\
John & M & 54 & NA & Las Vegas \\
Alfred & M & 51 & NA & Las Vegas \\
Cathy & F & 55 & NA & Las Vegas \\
Rhonda & F & 49 & NA & Las Vegas \\
Lourdes & F & 58 & NA & Las Vegas \\
\hline
\end{tabular}

Typical of ZMET studies, each interview lasted approximately ninety minutes. Participants were asked to bring pictures that represented their thoughts and feelings about their experience at the property and were then further questioned during each stage of the interview about their thoughts and feelings about the slot club. We decided not to ask directly about the slot club benefits before the in-depth interview to avoid the emphasis on particular benefits or requests for "freebies" that had characterized other studies. The ages of our participants ranged from forty-eight to seventy-five. The interviews were taped. ${ }^{9}$ The resulting data include 350 pages of verbatim transcribed interview texts and 56 images. We paid each tourist participant \$200 and each local participant \$100 in slot credits. Exhibit 1 displays demographic information about the participants (note that their real names have not been used).

\section{Analysis Procedure}

The data were coded by two researchers with previous experience using ZMET. The descriptions obtained during all steps of the ZMET process (i.e., photo probes, metaphor elicitation, and sensory images) generated constructs representing the customers' important thoughts and feelings about the mega casino resort and the slot club. It is important to note that we developed the constructs based on our data analysis. These constructs were then juxtaposed and linked to each other to represent the customers' mental models. In other words, when customers relate two ideas, the maps reflect that association by linking those constructs. For example, for locals, the idea that a customer knows his way around the property was represented by the construct "familiarity," which was related to the idea of being at home, represented by the construct "home/family feel." Constructs that appeared in at least

9. The Zaltman Metaphor Elicitation Technique (ZMET) is a patented research technique available for academics to use for academic purposes (if the users are properly trained) but must be licensed in for-profit business applications. In the present article, the mega casino covered the costs of recruiting for this study, to allow us to pursue this academic article. (The casino did not pay for our services or time in the study.) 
Exhibit 2:

Differences between the Locals and Tourist Slot Members

\begin{tabular}{ll}
\hline Tourists & \multicolumn{1}{c}{ Locals } \\
\hline Experience & \\
One overall positive experience & Club is inflexible, cold, businesslike \\
Being with family & Opportunity to meet others \\
Connection to other players & Connection to property \\
Value family feel & Value welcoming atmosphere \\
Bring up safety & Do not refer to safety as a concern \\
Perception of benefits & \\
Associated to exclusivity & Insufficient, commonplace \\
Bonus & Calculated value \\
Entitlement/reward & Entitlement/investment \\
Feel intimidated & Want control \\
\hline
\end{tabular}

half of the interviews were used to develop the mental models. When at least three participants related emerging constructs, those constructs were linked, forming a consensus map. During the analysis process, the two researchers separately examined the raw data to identify constructs, individually creating categories and allocating the constructs to such categories. Then we compared the resulting maps, finalizing them when we achieved consensus. We also looked for metaphors, because they can reveal underlying unconscious aspects of the players' experience, as well as cognitive process beyond those shown in more literal language (Zaltman 1996; Zaltman and Coulter 1995). Understanding these deep metaphors can help identify some of the implicit drivers of consumer behavior. In particular, we looked for references of physical motion, bodily sensations, and sensory experiences, following the recommendation of George Lakoff and Mark Johnson (1999): "[From a biological perspective,] it is eminently plausible that reason has grown out of the sensory and motor systems and that [reason] still uses those systems or structures developed from them. . . . [This] explains why our system for structuring and reasoning about events of all kinds should have a structure of a motor-control system" (cited in Zaltman 2003, 80).

\section{Results}

The consensus maps of local and tourist customers were in fact different. Exhibit 2 below summarizes the differences between tourist and local players.

One particularly interesting result was that tourists associate different meanings with the slot club than they do the resort, while locals see them as one entity. As Christine (a local) stated, "They are the same thing." Paradoxically, there were two consensus maps obtained for the locals, while only one map explained the feelings of the tourists. This choice of representation was based on the fact that even though tourists have different perceptions of experience at the property and at the casino, they consider these experiences to be related and their combination determines the decision to visit the property. For locals, on the other hand, there is one map that represents one overall perception, but the decision to patronize the mega resort is based on a rational analysis of the financial benefits acquired through the slot club.

\section{Meanings Elicited from Tourist \\ Customers}

For tourists, the experience at the mega resort casino property is luxurious, upscale, unique, and relaxing. "The whole experience 
Exhibit 3:

Tourist Consensus Map

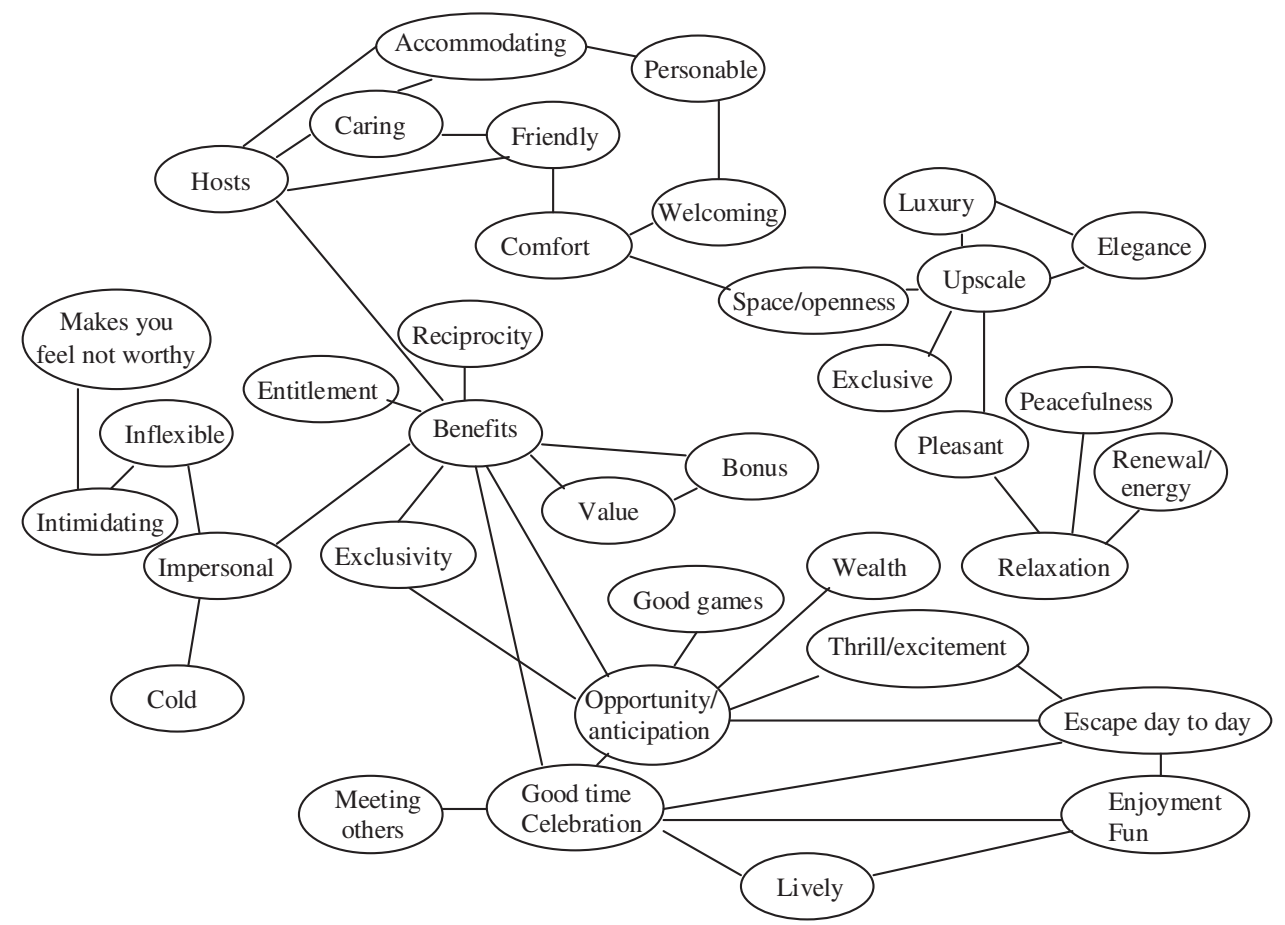

is pleasurable," said Miriam, from Florida. "It's a form of escapism . . . from the mundane existence of everyday life," commented Kristine, from Arizona. Tourists find the environment welcoming, comfortable, caring, friendly, and accommodating. As described by Penn, from California: "I feel very comfortable here. I know that I'm going to be taken care of. It's just a good feeling." Despite the positive qualities of the experience, only two tourists held an exclusive relationship with the property. Exhibit 3 shows in detail the tourists' consensus map of the resort experience and slot club.

The slot club, however, has few of the qualities that the tourists associate with the experience at the property. Tourists perceive the slot club as impersonal: "There isn't a lot of warmth there . . . there isn't a lot of hands-on, personal feelings" (Mia, from Illinois). "Bland," "cold," "rigid," and "plain" were some adjectives used to describe the club. The slot club conveys the idea that some players are not really worth its attention, and at times it is intimidating: "They make you feel like you don't gamble enough to be able to stay here" (Miriam, from Florida). With the exception of the hosts, the club staff members are not described as accommodating, contrasting with the welcoming and caring attributes of the resort experience.

There are, however, positive meanings ascribed to the slot club. One of them is exclusivity. There is a distinction that originates from membership in a slot club. In fact, some casino services can only be acquired through the slot clubs. Contrasting with airlines, where first-class tickets and access to VIP check-in are available to the general 
public, the player purchase history is usually what provides the access to personalized treatment and special invitations (e.g., the opportunity to attend special events and VIP check-in). The hosts, another element of the club with positive meanings, are described as accommodating, and they are associated with the exclusive character of the experience. In that regard, tourist players credit the hosts for their personalized treatment. The hosts act as intermediaries between the slot club and the customers by accommodating their needs.

Tourists regard the slot club benefits as a reward or a bonus. They feel they earned this bonus, and so there is a feeling of entitlement to the benefits: "Why would I want to go there and bother them, although I might be entitled to it, if they are going to make me feel that I'm not a valuable enough player?" (Elvira, from California). When the benefits do not correspond to customers' perceptions of what they are entitled to receive, the customers feel treated shabbily: not unique, not important, frustrated, and at times, intimidated. Among tourists there is an unwritten honor code: "You give me the stay, I give you my business. It is a good faith offer" (Kristine, from Arizona). This mutually beneficial relationship is shown in the consensus maps as the construct "reciprocity."

A deep metaphor that the tourists revealed relates to liveliness (or lack thereof). Tourist participants referred to the slot club as still, inflexible, not creative, and impersonal, but they were looking for an experience that is lively and fun. In addition, images of coldness associated with the club contrasted with the warmth of the experience elicited in the interviews. It is perceived as inanimate. It is not creative, and therefore not alive and ultimately not human. If we use metaphors of life and death to interpret those qualities, we conclude that the slot club is dead. This finding suggests that the slot club must convey the sense of life and human touch.
The second deep metaphor that surfaced in the tourist interviews was related to the idea of transformation, which involves moving from one state to another. The transformation begins when tourists are "escaping" their day-to-day life. With their overall experience at the property, they have the opportunity to relax and enter an atmosphere of luxury, joy, fun, and excitement. The only way the club relates to this transformation is by providing the opportunity to achieve wealth.

\section{Meanings Elicited from Local \\ Customers}

Locals revealed deeper emotional meanings from their experience at the property and with the slot club, such as friendship, safety, and warmth: "I think all of them know me by name" (Cathy). They feel at home, as described by Beatrice: "When we walk in the door and we smell the fragrance they have here we say, 'Oh, we're home." They feel surrounded by friends among the other players and the staff: "We're made to feel like we are among friends and family, people that care about us." (Julia).

Despite the deep emotions present in the locals' consensus maps, our research uncovered a cautionary note for the casino. The locals believe they can have similar experiences at other places. As a consequence, we found that their decision to patronize the property relies on a rational analysis of the value of the slot club package. Local customers are not reluctant to state that they are value driven, and if they think the deal is not good, they will go somewhere else. In Alfred's words, "It's just a matter of who's giving you the most for your money... which means having a good game that pays decent percentage back, some cash back, and good prizes." They would be willing to terminate the relationship if financial benefits were withdrawn without some form of compensation. 
Exhibit 4:

Locals Consensus Map
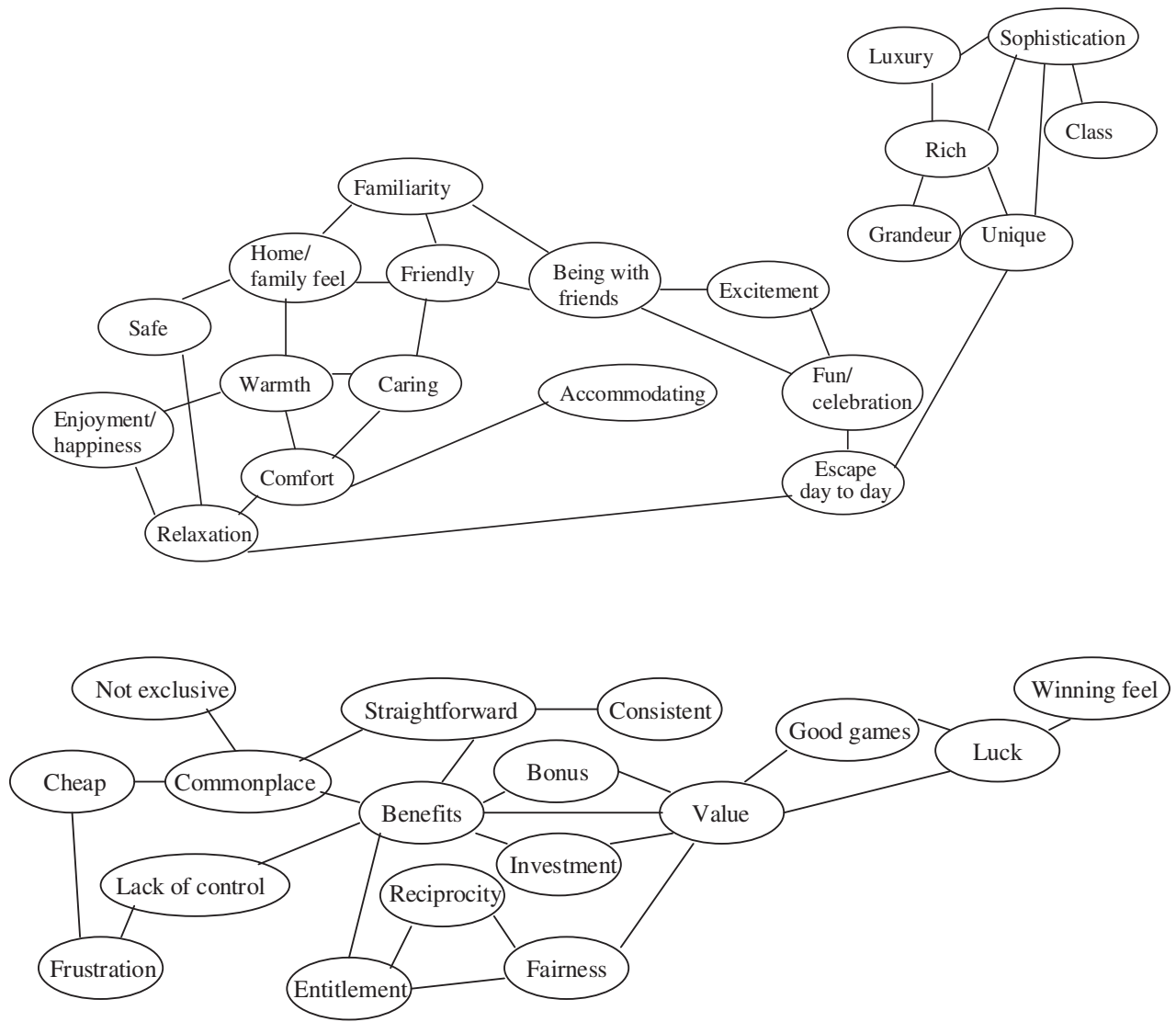

The locals have a clear understanding of the overall value of the product, evaluating the benefit package and estimating a price for their entertainment experience. Locals consider club benefits an entitlement, a self-acquired right: "I deserve it, because I've played enough" (Lourdes). Some locals described the benefits as an investment, expecting appropriate returns and clear criteria to qualify for benefits. Local customers experience feelings of lack of control when their eligibility to benefits does not correspond to their expectations, accompanied by frustration and anger: "They are just so cheap and chintzy. It's annoying" (Lourdes). Rather than a loyal relationship, the local customers and the casino seem to have developed a business relationship, described by Alfred, for instance, as a "give and take." Exhibit 4 shows the locals' consensus map of the combined resort and slot club experience.

Two deep metaphors were present in most interviews with locals: connection and control. The metaphor of control (or lack of control) arose in the interviews with locals when they described the benefits of the slot club, particularly the complimentary rooms and food offers. Locals 
stated clear preferences for criteria that would allow them to quantify their benefits along the lines of the miles in airline programs, even though they almost certainly know that the comps at the property studied are discretionary. The property does not have stated criteria for inviting the players to special events nor to offer complimentary stays and food.

The other important metaphor that emerged from the local interviews is connection. The local players associate the casino experience - and the slot club - with being with friends and feeling at home, safe, in a caring and comfortable environment. The interesting point, though, is that the connection to other local players and to the host seems to be stronger than the connection to the casino resort itself. For locals, the opportunity to interact with other players that they know is an integral part of the gambling experience. Their connection to other players seems to be more relevant than the connection to the property itself. Even though this phenomenon shares properties of brand communities, which describes "a friendship group of consumers with a shared enthusiasm for the brand and a welldeveloped social identity" (Bagozzi and Dholakia 2006), the community of local gamblers is formed without an attachment to the brand, in this case, the casino.

\section{Sensory Analysis: Overall Feelings about the Slot Club}

The sensory descriptions of the club were similar for locals and tourists. For both groups, the sensory analysis reveals meanings with either neutral or negative connotation. Examples of colors associated were the club were either dark, such as blue or black (representing sadness and stillness), or neutral, such as taupe and beige (representing indifference). The textures were plain (e.g., cotton), and tastes were bland (e.g., potatoes, bananas). The resort, in contrast, was described with vibrant, rich, and luxurious colors (e.g., red and gold) and textures (e.g., velvet). Calming sounds such as jazz and classical music described the property, contrasting with annoying and irritating sounds for the club like hissing machines or a motor running.

\section{Discussion}

The results of the study indicate that the slot programs are considered commonplace, in considerable contrast with the distinctive meanings of the resort's service and atmosphere. Such a discrepancy may be the case for most loyalty programs in the market, but participants were not particularly impressed with the club. Worse, the interactions with the slot club staff and the club's policies reflect negatively on the perception of the experience at the resort.

That said, the deep meanings of locals and tourists are different; therefore, they must be treated differently. For tourists, the deep meanings associated with the club must be changed to establish meaningful relationships and build on emotional connections. In the current model, only the hotel staff and the hosts are perceived as accommodating. Human qualities such as care and creativity, as well as the ideas of luxury and relaxation, are lacking in the current casino loyalty program. This was clearly expressed with images of life that contrasted sharply with descriptions of the slot club.

Instead, the slot club must convey a sense of flexibility. For example, its operators should respond to customer needs without intermediation from hosts. The process must be revitalized so that any team member in the slot club can cater to the customers' needs. Another important requirement is a widespread focus on establishing meaningful relationships. Slot club membership must reflect the warm, welcoming, and caring attitude of the resort staff. In 
addition, the slot club should reflect the characteristics presented by the casino, namely, fantasy, luxury, elegance, sophistication, friendliness, and comfort. The slot club will probably benefit from increasing efforts to portray those features in the design of the tournaments, invitations, and offers.

For local customers, the overall perception of the club is aligned with the exclusive and high-end image of the property. However, even though locals do not clearly differentiate their experience with the slot club and the overall experience at the property, their decision making occurs on a more rational level, based on the value of the benefit package.

\section{Implications: What We Told Management}

As we said, the results of this study indicate differences between locals and tourists in the deep meanings associated with the resort experience and the slot club. Therefore, the casino management should have different priorities when designing marketing efforts for each of these markets. When deciding where to play, tourists emphasize the experience, while locals look for value of the benefit package.

In the case of tourists, the perceptions of the slot club contrast harshly with the feelings of uniqueness, luxury, extravagance, and escapism that draw them to the property. Even though the tourists know that the slot club is the mechanism to make their experience more personalized and exclusive, they do not ascribe deep meanings of luxury to the club. The casino could benefit from adding upscale features to the slot club's tangible elements such as décor of the slot club booths and promotional material. The club must portray human qualities such as creativity, flexibility, and care.

All members of the slot club staff (rather than mainly the hosts) should be able to accommodate club members' needs and develop relationships. The slot club staff members may need to be empowered, for instance, by having autonomy to assign comps and benefits according to a player's level. In addition, they may need to be trained to develop the caring and friendly attitude attributed to other representatives of the resort (particularly the hotel staff). A possible strategy to change the staff members' approach to their duties is to establish a parallel between each person's position and the hosts. In addition, a job description that minimizes monotonous and time-consuming activities could free the slot club team members to interact pleasantly with the customers. Automating repetitive transactions such as the redeeming processes through self-serve kiosks or the website can help the property achieve those goals. In addition, the system must allow "transferring" the relationships between different slot club representatives, including hosts. One of the requirements for such ability is having the right information about the customers available in different points of contact for team members. Furthermore, having a customer profile that can be updated directly by the gamers either online or on property, bypassing the hosts, could increase the casino's ability to cater to customer needs.

For locals, the property in the study has established a desirable overall experience with strong emotional bonds. However, these people focus on the value of the overall experience package. This is what drives the purchase decision and establishment of an enduring relationship. The locals' desire for control could be fulfilled with a more transparent reward systemone that allows members to see where they stand-although comps remain at the discretion of management. A beneficial continuous presence in this market will require a careful analysis of lifetime profitability of these customers. The property must be careful with the design of offers, 
particularly when they involve interdepartmental efforts, to maintain adequate levels of profitability and avoid losses.

\section{Managerial Response to the Study Findings}

The property made significant changes in its slot club based on the findings in this study. The managers adopted the recommendation to give the players control over their comps. For instance, club members can now use their cash-back points in exchange for cash, promotional credits, or gift cards at different exchange rates. Additionally, the casino conducts fewer events but those it does produce offer greater entertainment and higher prizes. The events have themes, in an attempt to make them unique, alive, and appealing to the customer. According to management, the attendance at events has increased almost 50 percent. Even though the events are less frequent, overall profits seem to be increasing, along with customer satisfaction.

In addition, with its enhanced understanding of the customer decision process, the property now uses a more comprehensive approach to assess the players' profitability. Instead of analyzing marketing efforts in isolation, management calculates profitability of individual customers based on the combination of promotional offers they receive (e.g., cash back, coupons, events, comps). Such analysis allows identification and exclusion of unprofitable customers from the mailing lists. Furthermore, the casino is implementing self-service kiosks to automate coupon and cash-back redemption, making such processes faster, more reliable, and less inconvenient. The casino is also redesigning the job of the slot club attendants and considering new training efforts to help the attendants understand their role in accommodating customers' needs, thereby improving the slot club human aspects.

\section{Beyond Casinos: Implications for Loyalty Programs}

The questions regarding customer loyalty that this casino resort faced with its frequent-player program are by no means restricted to the gaming industry. This study suggests that the concept of loyalty as defined by Oliver (1999) ${ }^{10}$ does not explain the relationship between the frequent slot customers, the casino, and its slot club. Even though the experience is characterized by deep emotional meanings, this does not guarantee an exclusive relationship, and we found mediating variables that influence the relationship of casino and customer, such as the hosts, the slot club staff, and other customers.

Theoretical frameworks that look at the nature of relationships, as well as frameworks that apply network theory, might better explain the behavior of casino frequent customers than do theories on customer loyalty. In addition, the idea of reciprocity that pertains to the relationships of the casino with locals and with tourists suggests that rather than inquiring about customers' loyalty to the casino, casinos might switch the question to, "How can I show loyalty to the customer?" This finding is congruent with Shugan's (2005, 185) observation: "Rather than showing trust by committing to the customer, the firm asks the customer to trust the firm - that is, trust that future rewards are indeed forthcoming. A true loyalty program invests in the customer (e.g., provides free up-front training, allows familiarization or customization) with the expectation of greater future revenue."

10. Oliver (1999) defined loyalty as "a deeply held commitment to rebuy or repatronize a preferred product/ service consistently in the future, thereby causing repetitive same-brand or same brand-set purchasing, despite situational influences and marketing efforts having the potential to cause switching behavior" (p. 34). He continued to define ultimate loyalty as when the consumer "fervently desires to rebuy a product or service and will have no other," and will pursue this quest "against all odds and at all costs" (p. 35). 
This study exemplifies how the ZMET technique can provide valuable insights in the study of loyalty programs in casinos and possibly other segments of the hospitality industry. As indicated by the results, even though the outcome of a traditional study had generated a list of traditional financial rewards to be implemented in a loyalty program, the financial benefits are not related to loyalty in either the local or the tourist segment. A possible follow-up for this study could be based on pictures representing the loyalty program itself. Other hospitality researchers might find this methodology useful for understanding their customers' deep emotional ties to their industry.

\section{References}

Backman, S. J., and J. L. Crompton. 1991. Differentiating among high, spurious, latent, and low loyalty participants in two leisure activities. Journal of Park and Recreation Administration 9 (2): 1-17.

Bagozzi, Richard P., and Utpal M. Dholakia. 2006. Antecedents and purchase consequences of customer participation in small group brand communities. International Journal of Research in Marketing 23 (1): 45-61.

Baloglu, Seyhmus. 2002. Dimensions of customer loyalty: Separating friends from well wishers. Cornell Hotel and Restaurant Administration Quarterly 43 (1): 47-59.

Barsky, Jonathan, and Leonard Nash. 2002. Evoking emotion: Affective keys to hotel loyalty. Cornell Hotel and Restaurant Administration Quarterly 43 (1): 39-46.

Braun-LaTour, Kathryn A., Flavia Hendler, and Rom Hendler. 2006. Digging deeper: Art museums in Las Vegas? Annals of Tourism Research 33 (1): 265-68.

Brokopp, John G. 2006. Casino deals bad hand to video poker players. Chicago Sun-Times, May 19.

Browne, Beverly A., Dennis Kaldenberg, and Daniel J. Brown. 1992. Games people play: A comparative study of promotional game participants and gamblers. Journal of Applied Business Research 9 (1): 93-99.

Damasio, Antonio. 1994. Descartes' error, emotion, reason, and the human brain. New York: Putman.

Day, George S. 1969. A two-dimensional concept of brand loyalty. Journal of Advertising Research 9:29-35.

Dick, Alan S., and Kunal Basu. 1994. Customer loyalty: Toward an integrated conceptual framework. Journal of the Academy of Marketing Science 22 (2): 99-113.

Domenici, Nicole. n.d. My favorite spots in Las Vegas. Going Places. http://www.pbs.org/wnet/archive/goingplaces1/ lasvegas-fav2.html (accessed March 15, 2007).
Dowling, Grahame R., and Mark D. Uncles. 1997. Do customer loyalty programs really work? Sloan Management Review 38 (4): 71-82.

Fournier, Susan, and Julie L. Yao. 1997. Reviving brand loyalty: A reconceptualization within the framework of consumer-brand relationships. International Journal of Research in Marketing 14 (5): 451-72.

Hallberg, Garth. 2004. Is your loyalty programme really building loyalty? Why increasing emotional attachment, not just repeat buying, is key to maximising programme success. Journal of Targeting, Measurement and Analysis for Marketing 12 (3): 231-41.

Hirschman, Elizabeth C., and Morris B. Holbrook. 1982. Hedonic consumption: Emerging concepts, methods and propositions. Journal of Marketing 46 (3): 92-101.

Jacoby, Jacob, and Robert W. Chestnut. 1978. Brand loyalty: Measurement and management. New York: John Wiley.

Jacoby, Jacob, and David B. Kyner. 1973. Brand loyalty vs. repeat purchasing behavior. Journal of Marketing Research 10 (1): 1-9.

Jeffery, Mark, and Ingmar Leliveld. 2004. Best practices in IT portfolio management. MIT Sloan Management Review 45 (3): 41-49.

Lackoff, George, and Mark Johnson. 1999. Philosophy in the flesh: The embodied mind and its challenge to Western thought. New York: Basic Books.

Loveman, Gary. 2003. Diamonds in the data mine. Harvard Business Review 81:109-13.

Lucas, Anthony F., Jim Kilby, and Jocelina Santos. 2002. Assessing the profitability of premium players. Cornell Hotel and Restaurant Administration Quarterly 43 (4): 65-78.

Mattila, Anna S. 2001a. Emotional bonding and restaurant loyalty. Cornell Hotel and Restaurant Administration Quarterly 42 (6): 73-79.

. 2001b. The impact of relationship type on customer loyalty in a context of service failure. Journal of Service Research 4 (2): 91-101.

-2006. How affective commitment boosts guest loyalty (and promotes frequent-guest programs). Cornell Hotel and Restaurant Administration Quarterly 47 (2): 174-81.

Oliver, Richard L. 1999. Whence consumer loyalty? Journal of Marketing 63:33-44.

Pinker, Steven. 1994. The language instinct: How the mind creates language. New York: W. Morrow. - 1997. How the mind works. New York: Norton.

Pritchard, Mark P., Mark E. Havitz, and Dennis R. Howard. 1999. Analyzing the commitment-loyalty link in service contexts. Journal of the Academy of Marketing Science 27 (3): 333-48.

Sharp, Byron, and Anne Sharp. 1997. Loyalty programs and their impact on repeat-purchase loyalty patterns. International Journal of Research in Marketing 14 (5): 473-86.

Shugan, Steven M. 2005. Brand loyalty programs: Are they shams? Marketing Science 24 (2): 185-93.

Stauss, Bernd, Maxie Schmidt, and Andreas Schoeler. 2005. Customer frustration in loyalty programs. International Journal of Service Industry Management 16 (3): 229-52. 
Stutz, Howard. 2007. Arizona Charlie's executive aims to boost client count with warm welcomes. Las Vegas Review-Journal, February 19.

Uncles, Mark D., Grahame R. Dowling, and Kathy Hammond. 2003. Customer loyalty and customer loyalty programs. Journal of Consumer Marketing 20 (4): 294-316.

Whyte, Randall. 2004. Frequent flyer programmes: Is it a relationship, or do the schemes create spurious loyalty? Journal of Targeting, Measurement and Analysis for Marketing 12 (3): 269-80.

Wirtz, Jochen, Anna S. Mattila, and May O. Lwin. Forthcoming. How effective are loyalty reward programs in driving share of wallet? Journal of Service Research.
Yi, Youjae, and Hoseong Jeon. 2003. Effects of loyalty programs on value perception, program loyalty, and brand loyalty. Journal of the Academy of Marketing Science 31 (3): 229-40.

Zaltman, Gerald. 1996. Metaphorically speaking. Marketing Research 8 (2): 13-20.

. 1997. Rethinking market research: Putting people back in. Journal of Marketing Research 34 (4): 424-37.

- 2003. How customers think. Cambridge, MA: Harvard Business School Press.

Zaltman, Gerald, and Robin Hige Coulter. 1995. Seeing the voice of the customer: Metaphor-based advertising research. Journal of Advertising Research 35 (4): $35-51$.

Flavia Hendler is a Ph.D. candidate in the William F. Harrah College of Hotel Administration at the University of Nevada, Las Vegas (fhendler@unlv.nevada.edu), where Kathryn A. Braun-LaTour is an assistant professor of hospitality marketing (kathryn.latour@unlv.edu). 